\title{
Innovative composite on the basis of an aerogel mat with an epoxy resin modified with PET waste and PCM
}

\author{
Bernardeta Dębska ${ }^{1, *}$, Lech Lichołai $^{1}$, and Jerzy Szyszka ${ }^{1}$ \\ ${ }^{1}$ Rzeszow University of Technology, The Faculty of Civil and Environmental Engineering and \\ Architecture, Poznanska 2, 35-082 Rzeszow, Poland
}

\begin{abstract}
The article presents a patent proposition of a composite sandwich panel made of aerogel mat and a composition of encapsulated phase-change material PCM and epoxy resin modified by glycolysis based on poly(ethylene terephthalate) waste. A multifunctional thermal insulation material with a large heat capacity was obtained. This ability makes it possible to limit the temperature fluctuation in the space encased with the composite. In addition, thanks to the use of aerogel mat, which is characterized by much higher thermal insulation than commonly available materials, it is possible to achieve the assumed thermal resistance using more than two times lower thickness of insulation. The combination of aerogel and resin-PCM makes it possible to give the material virtually any shape. After the hardening process is completed, it has incomparably greater tensile, bending and compression strengths than Styrofoam and mineral wool. These features predispose it for use in situations where high thermal insulation is required while maintaining a low thickness of insulation material and a large thermal capacity of the housing material is indicated, e.g. thin divisions used in passive buildings, window joinery elements, engine compartments and cabin components in vehicles, household appliances etc.
\end{abstract}

\section{Introduction}

Sandwich structures have been used in industry since the beginning of the $20^{\text {th }}$ century as light solutions enabling high bending strength. Currently, these composites play an important role in many applications, including construction, wind energy, logistics, shipping, aviation and the motor industry. The sandwich structure is a composite material that consists of rigid outer layers and a relatively soft core.

These materials have long been attractive to designers and they can still be seen to be developing. A modern sandwich structure, along with its favourable strength parameters, should also bring economic benefits by reducing weight and production costs. Attention should also be paid to additional functionalities, for example thermal and sound insulation. The use of recycled materials is an important aspect [1-6]. The core of the sandwich panel

\footnotetext{
* Corresponding author: bdebska@prz.edu.pl
} 
can be materials such as balsa [6, 7], light concrete reinforced with PP fibres [1], polyurethane foam [3], aluminium foam [2, 8, 9]. Interesting solutions for sandwich structures were also obtained using epoxy honey comb [4], expanded cork [10], epoxy resin filled with alumine tri-hydrate (ATH) particles [11], cross-linked polyvinyl chloride foam and poly(ethylene) terephthalate (PET) foam [6], and even bottle caps [5] Attempts have also been made to obtain sandwich structures containing PCM $[12,13]$ or aerogel $[14,15]$, but only combining the latter two materials allows us to obtain a multifunctional material, at the same time having the ability to stabilize the temperature of the insulated space and a thermal resistance much higher than the commonly available insulating materials.

When designing a space intended for human use, particular attention is paid to reducing the heat exchange through external partitions separating the interior from the external environment. Protection against excessive cooling of the air in the winter and against overheating in the summer is most often ensured by the use of materials with high thermal resistance. A wide range of thermal insulation based on polystyrenes, polyurethanes, polyisocyanurates or rock wool is being successively enriched with innovative materials with increasingly better parameters. These include VIP [16] panels and a variety of aerogels [17-19]. Aerogel mat has a particularly high potential due to a low heat conduction coefficient of $0.016 \mathrm{~W} / \mathrm{mK}$ and its ability to take various shapes. Its main ingredient is aerogel.

Aerogel production uses chemical methods involving the reaction of extremely thinned tetrafunctional alkoxysilanes with water vapour (e.g. $\left.\mathrm{Si}\left(\mathrm{OCH}_{3}\right)_{4}\right)$ in an inert gas atmosphere. In the first stage, a soft silica gel is formed due to hydrolytic condensation. Before the resulting silica foam solidifies completely, the pressure in the reactor is slowly decreased until an almost complete vacuum is obtained, resulting in a sharp increase in the gel volume. At the final stage of production, the reactor is filled with an inert gas and the temperature is raised at the same time, which leads to completion of the condensation reaction, stiffening of the foam and formation of a durable aerogel. The structure of the aerogel consists of a rigid skeleton reminiscent of a spatial lattice surrounding pores of size $10-200 \mathrm{~nm}$. The porosity ranges from 90 to more than $99 \%$. The density, depending on the production method, ranges from 2 to several dozen $\mathrm{kg} / \mathrm{m}^{3}$ [17]. The excellent thermal insulation of aerogel is primarily due to the limitation of conduction and convection processes. This is possible due to the specific structure of this material, whose pore dimensions are comparable to the free path of air particles. Commercial aerogel insulations are available in many forms: granules, tapes, boards and mats.

Thermal insulation materials significantly limit the heat transfer through the partition in which they have been incorporated; however, due to their low bulk density value they have negligible thermal capacity. This property limits the ability to temporarily store heat, which is important when they are used to make housings, for example in buildings with frame construction, cabins intended for people at work, residential and office containers, etc. The ability to store heat is important in shaping the thermal comfort of rooms. Housing material characterized by a high thermal capacity allows reductions in the fluctuations in air temperature in the room. This feature is proportional to the values of bulk density and specific heat, unfortunately they are antagonistic to the properties of typical thermal insulation materials.

The paper presents the results of tests carried out on a composite, the core of which was made of aerogel mat while the outer layer was a composition of epoxy resin modified with poly(ethylene terephthalate) (PET) glycolisate with phase change material (PCM). PCMs are substances that have a large heat capacity. This property results from the so-called phase transformation heat, which accompanies the change of phase (usually from solid to liquid) after exceeding a certain temperature dependent on the composition of the material (Fig.1). 


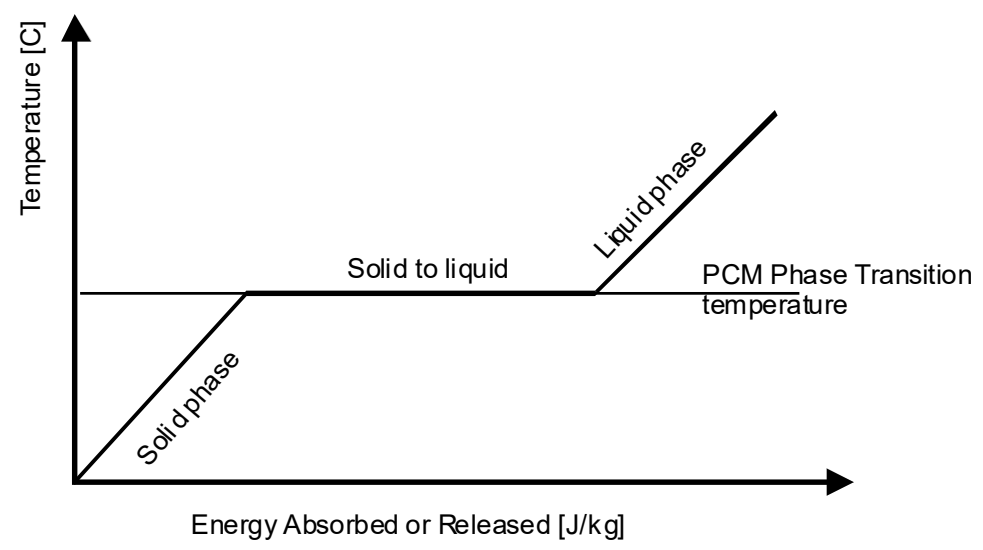

Fig. 1. Ilustration of PCM phase transformation as a function of temperature.

The combination of aerogel mat with PCM enables the technology described in the patent application [20] assuming the application of a mixture of a modified epoxy resin with a capsule-formed phase change material (Micronal BASF) [21] prepared in defined proportions. The composite formed after the hardening process of the resin can have virtually any shape and much higher bending strength than the aerogel mat itself (Fig. 2).

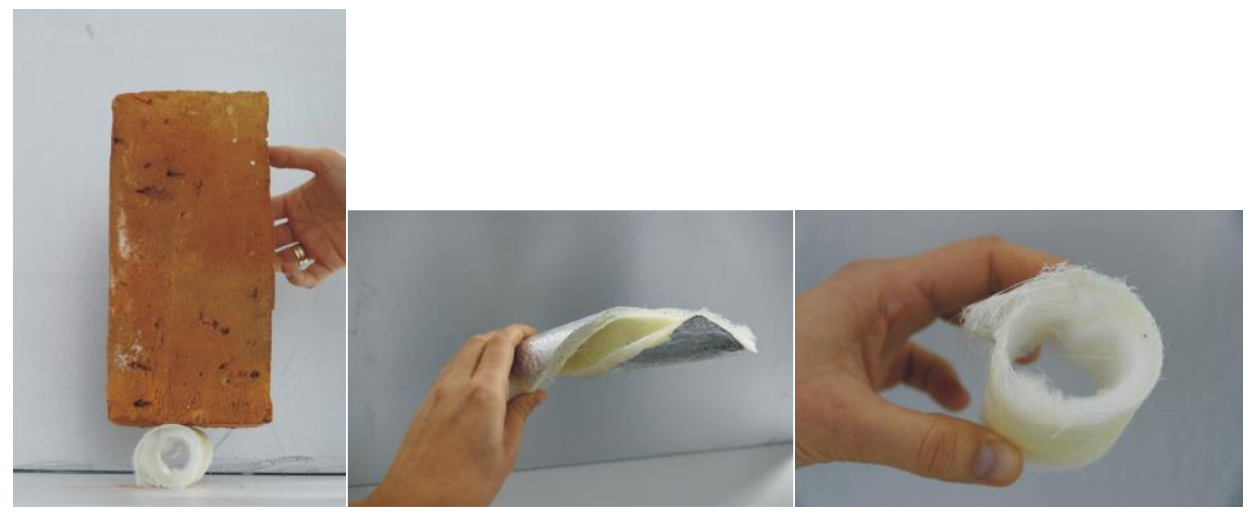

Fig. 2. The possibilities of shaping the composite.

\section{Materials and methods}

The commercial epoxy resin composition used in the tests was Epidian 5 (with selected properties shown in Table 1) in which $9 \%$ wt. of the resin was replaced by glycolysate. This modifier was obtained in a glycolysis process in which propylene glycol and waste polyethylene terephthalate (PET) were used. The glycolyzate for the tests was obtained from one of the chemical plants operating in Poland. A short characterization of the conditions of the obtaining process and selected properties of PET glycolysate are presented in the table 2. After mixing the epoxy resin and the modifier were heated to $85^{\circ} \mathrm{C}$ for 1 hour. The content of the modifier in the mixture was selected based on previous studies of resin composites [22-27]. The composition containing the modifier is characterized by better strength parameters, excellent chemical resistance, and additionally it is more flexible compared to the standard resin [28]. 
Table 1. Selected parameters characterizing Epidian 5 epoxy resin.

\begin{tabular}{|c|c|c|c|c|}
\hline Type of resin & $\begin{array}{c}\text { Density } \\
{\left[\mathbf{g} / \mathbf{c m}^{3}\right]}\end{array}$ & $\begin{array}{c}\text { Viscosity } \mathbf{2 5}^{\circ} \mathbf{C} \\
{[\mathbf{m P a} \mathbf{~}]}\end{array}$ & $\begin{array}{c}\text { Molecular weight } \\
{[\mathbf{g} / \mathbf{m o l}]}\end{array}$ & $\begin{array}{c}\text { Epoxy number EN } \\
{[\mathbf{m o l} / \mathbf{1 0 0 g}]}\end{array}$ \\
\hline Epidian 5 & 1.17 & 30000 & 450 & 0.49 \\
\hline
\end{tabular}

Table 2. Selected properties and short characterization of the conditions in which the PET glycolysate was obtained.

\begin{tabular}{|l|c|c|c|c|c|c|c|}
\hline $\begin{array}{c}\text { Kind of glycol used } \\
\text { in the glycolisation } \\
\text { process }\end{array}$ & $\begin{array}{c}\bar{M}_{n} \\
{[\mathbf{g} / \mathbf{m o l}]}\end{array}$ & $\begin{array}{c}\bar{M}_{w} \\
{[\mathbf{g} / \mathbf{m o l}]}\end{array}$ & $\mathbf{P}_{\mathbf{d}}$ & PET & Glycol & $\begin{array}{c}\text { Temperature } \\
{\left[{ }^{\circ} \mathbf{C}\right]}\end{array}$ & Catalist \\
\hline propylene & 305 & 410 & 1.34 & 1 & 1.7 & 210 & $\begin{array}{c}\text { zinc } \\
\text { acetate }\end{array}$ \\
\hline $\begin{array}{l}\bar{M}_{n} \text { - numerically mean molecular weight, } \bar{M}_{w} \text { - by weight mean molecular weight } \\
\mathrm{P}_{\mathrm{d}} \text { - degree of polydispersion }\end{array}$
\end{tabular}

It is noteworthy that the use of recycled materials (waste PET) as epoxy resin modifiers brings significant environmental benefits. The resin and modifier composition was cooled to room temperature and then mixed with the Z-1 hardener (triethylenetetramine) and combined with the encapsulated phase-change material in the amount of $70 \% \mathrm{wt}$. in relation to the weight of the resin. Selected parameters of the phase-change material are summarized in Table 3.

Table 3. Selected parameters characterizing encapsulated phase-change material www.basf.de.

\begin{tabular}{|c|c|c|c|c|}
\hline $\begin{array}{c}\text { Type of } \\
\text { PCM }\end{array}$ & $\begin{array}{c}\text { Melting } \\
\text { point }\left[{ }^{\circ} \mathrm{C}\right]\end{array}$ & $\begin{array}{c}\text { Thermal capacity } \\
{[\mathrm{kJ} / \mathrm{kg}]}\end{array}$ & $\begin{array}{c}\text { Bulk density } \\
{\left[\mathrm{kg} / \mathrm{m}^{3}\right]}\end{array}$ & $\begin{array}{c}\text { Enthalpy of fusion } \\
{[\mathrm{kJ} / \mathrm{kg}]}\end{array}$ \\
\hline $\begin{array}{c}\text { Micronal DS } \\
5008^{\circledR}\end{array}$ & 23 & 136 c.a. & $250-350$ & ca. 100 \\
\hline
\end{tabular}

The thus prepared mixture was applied to aerogel mat previously cut to the assumed dimensions. The basic thickness of the resin composition was $10 \mathrm{~mm}$ and a single mat of 5 $\mathrm{mm}$. Several variants were considered depending on the thickness of the aerogel mat applied. The article omits the influence of external composite finishing layers on its thermal properties. Depending on the way the composite is used, the choice of the outer layer is practically free; paint coating, upholstery, veneer, laminate, aluminium foil, etc.

The heat transfer coefficient tests were carried out using the NETZSCH HFM436 plate apparatus shown in Figure 3a.

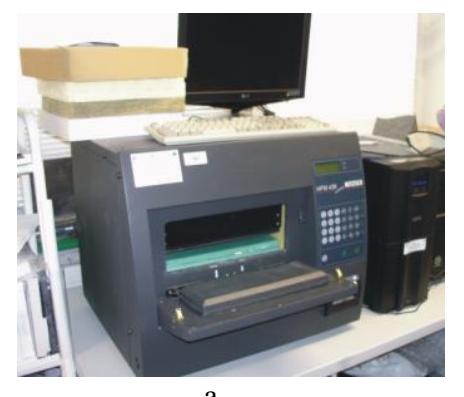

a

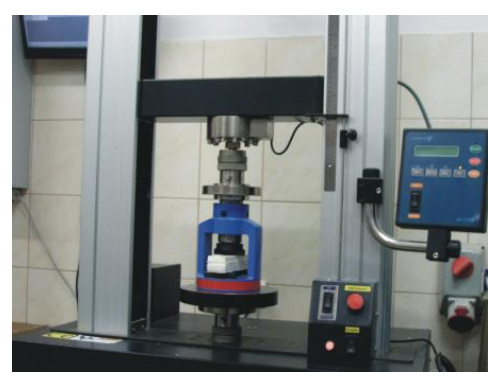

b

Fig. 3. Measuring apparatus used in the tests: a) NETZSCH plate apparatus, b) universal strength testing machine QCTECH. 
The bending strength test was carried out in a strength testing machine equipped with a suitable insert (Figure 3b), in accordance with the PN-EN 196-1:2006 standard.

\section{Results and discussion}

In the design of a sandwich composite, knowledge of the value of its thermal resistance and thermal capacity is important. The heat transfer coefficient tests confirmed the possibility of prediction of thermal resistance (the coefficient of determination was 0.915) of the composite based on equation (1). The dependence of the thermal conductivity coefficient of the aerogel mat as a function of its thickness is shown in Fig. 4.

$$
R=\frac{d_{a}}{\lambda_{a}}+\frac{d_{c}}{\lambda_{c}} \quad\left[\frac{m^{2} \cdot K}{W}\right]
$$

where:

$d_{a}$ - thickness of the aerogel mat insert [m],

$d_{c}$ - thickness of the resin-PCM composition [m],

$\lambda_{a}-$ thermal conductivity of the aerogel mat, $\lambda_{\mathrm{a}}=0.0724 \cdot d+0.0158 \mathrm{~W} / \mathrm{mK}$

for the field $\mathrm{d} \in<0.005 ; 0.04>$

$\lambda_{c}-$ conduction coefficient of the resin composition-70\% wt. PMC, $\lambda_{c}=0.09868 \mathrm{~W} / \mathrm{mK}$.

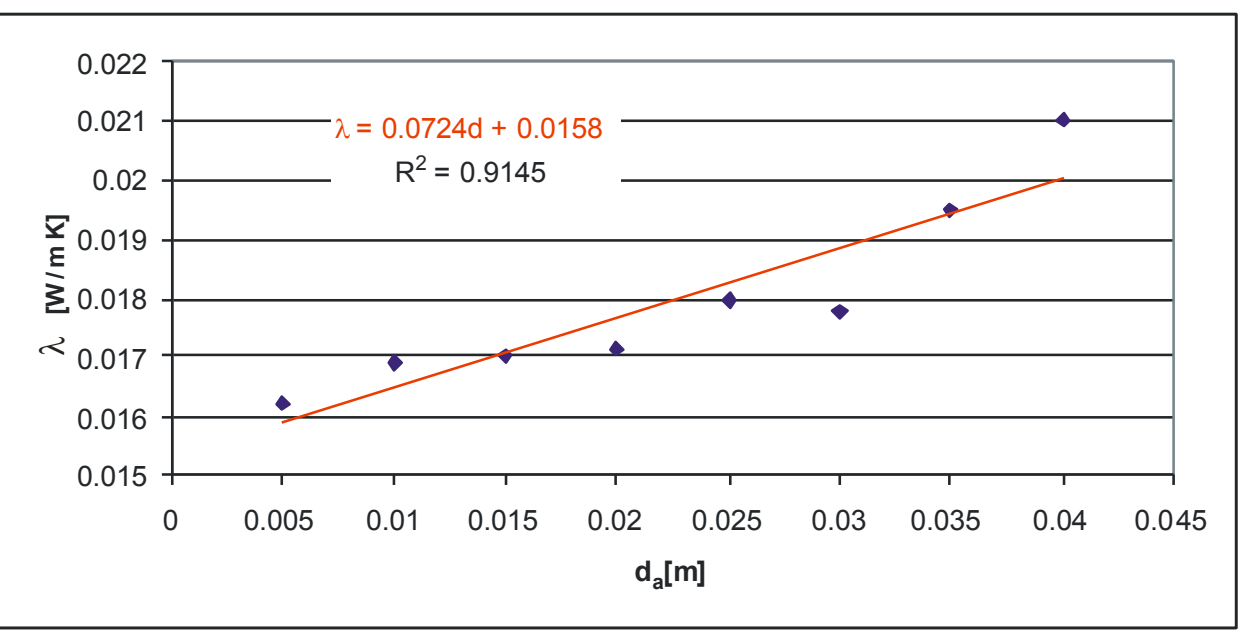

Fig. 4. The dependence of the thermal conductivity coefficient of the aerogel mat as a function of its thickness.

Determination of the heat conduction coefficient of the composite was carried out for different variations of mat configuration with PCM resin mixture.

The value of the thermal capacity of the composite understood as the ability to store heat $\mathrm{Q}$ depends on the ambient temperature and can be estimated with the equation (2):

$$
Q=Q_{1}+Q_{2}+Q_{3}
$$

$Q_{1}$ - heat stored at a temperature not exceeding the phase change temperature of the PCM material (eq. 3), 


$$
Q_{1}=\left(T_{m}-T_{a 1}\right) \cdot c_{p_{S}} \cdot m_{c},
$$

$Q_{2}$ - heat stored at ambient temperature above the PCM phase change temperature (eq. 4),

$$
Q_{2}=m_{P C M} \cdot C_{H}
$$

$Q_{3}$ - heat stored at ambient temperature above the PCM phase change temperature from the moment of complete phase change of the PCM material (eq. 5),

$$
Q_{3}=\left(T_{a 2}-T_{m}\right) \cdot c_{p F} \cdot m_{c},
$$

$T_{m}$ - melting point,

$T_{a 1}, T_{a 2}$ - ambient temperature $\left(T_{a 1}<T_{C H}, T_{a 21}>T_{C H}\right)$,

$c_{p S}$ - specific heat of the composition before phase change occurs in the PCM component,

$c_{p F}$ - specific heat of the composition after phase change in the PCM component,

$m_{c}$ - mass of resin-PCM composition.

The combination of composite components and fixation of the final shape while maintaining a bending strength of $4.52 \mathrm{MPa}$ is possible due to the use of the properties of modified epoxy resin.

The composite bending test results presented in Figure 5 showed a dependence on the thickness of the components used in the composite; aerogel mat in the tensile zone and resin-PCM composition in the compression zone. The tests found an increase in the strength of the composite primarily along with an increase in the thickness of the mixture. The influence of the thickness of the aerogel mat in this aspect was less important. While its influence on the bending strength of the composite was not significant, its ability to reduce the breakdown of the composite can be considered as a beneficial factor. After rupture of the composition, it was not detached from the mat, as shown in fig. 6 .

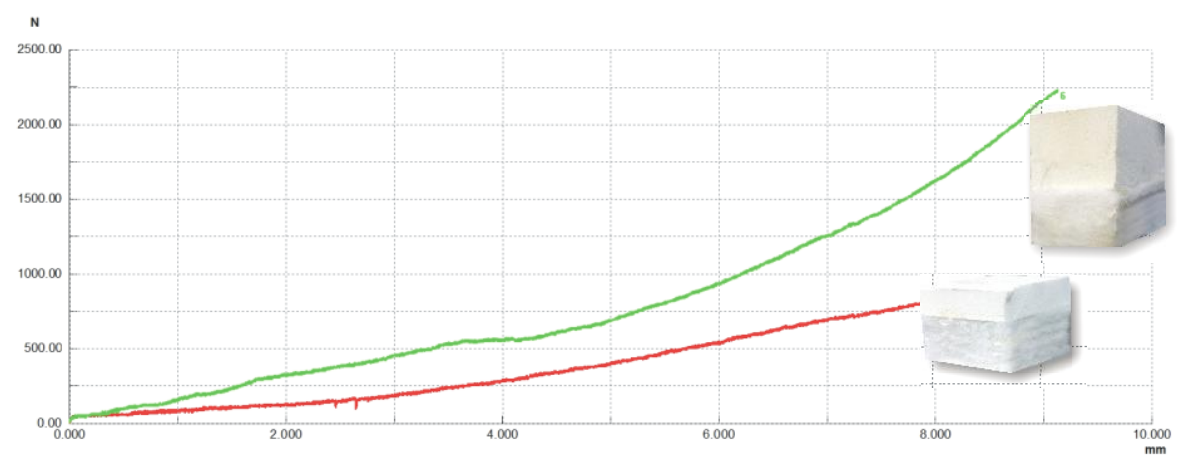

Fig. 5. Diagram of force-displacement relation for different thicknesses of the composite.

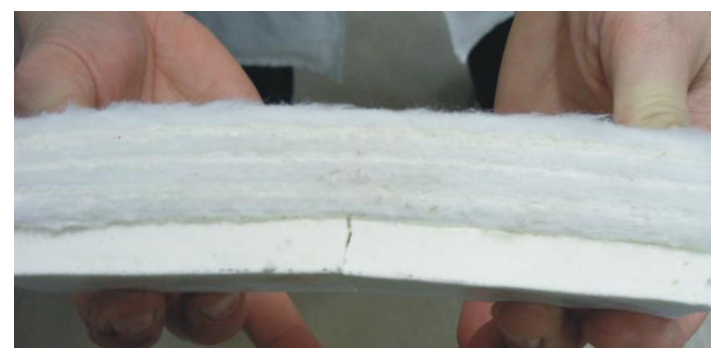

Fig. 6. View of an example sample after the bending strength test. 
Even after the PCM resin composition has cracked, the composite can still perform its function.

Graphs of the thermal resistance of the composite as a function of the thicknesses of the mat and mix are given in Figure 7.

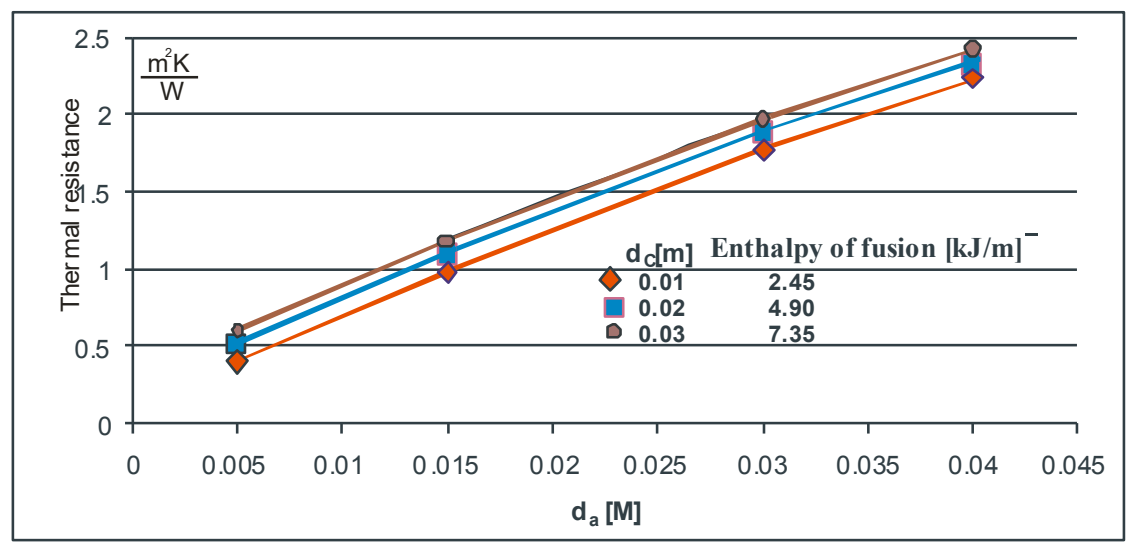

Fig. 7. Graphs of the thermal resistance of the composite as a function of the thicknesses of the mat and mix.

\section{Conclusions}

The results of the conducted tests confirm the usefulness of combining the materials discussed. The properties of the composite obtained, while maintaining the positive attributes of the individual materials, at the same time reduce their weaknesses. The aerogel mat retains the excellent properties of the thermal conductivity coefficient (ca. $0.016-0.020 \mathrm{~W} / \mathrm{mK}$ ) and protects the resin-PCM composition against breakdown and degradation under the influence of UV radiation. Depending on the thickness of the mat and the composition, thermal resistance takes values from approx. $0.41 \mathrm{~m}^{2} \mathrm{~K} / \mathrm{W}$ for a mat thickness of $0.005 \mathrm{~m}$ and composition $0.01 \mathrm{~m}$, to approx. $2.44 \mathrm{~m}^{2} \mathrm{~K} / \mathrm{W}$ for mats and compositions with a thickness of $0.03 \mathrm{~m}$. The PCM-resin composition allows mats to be created in even complex shapes, while increasing the thermal capacity of the composite depending on the thickness of the composition by ca. $2.45 \mathrm{~kJ} / \mathrm{m}^{2}$ for every $\mathrm{cm}$ of the composition. The incorporation of a waste PET glycolysis resin into PCM resin composition results in increased elasticity of the hardened composite. In addition, it brings ecological and economic benefits, in keeping with the idea of sustainable development in construction.

\section{References}

1. C. Frazão, J. Barros, R. Toledo Filho, S. Ferreira, D. Gonçalves, Cem. Concr. Compos. 86, 206-223 (2018)

2. G. Sun, X. Huo, D. Chena, Q. Li, Mater. Design 133, 154-168 (2017)

3. M. Saras Chandra, M. Ramya, E. Suresh, K. Padmanabhan, Mater. Today: Proceedings 4, 8856-8865 (2017)

4. A.U. Ude, A.K. Ariffin, C.H. Azhari, Int. J. Impact Eng. 58, 31-38 (2013) 
5. P. Resende Oliveira, A.M. Silva Bonaccorsi, T. Hallak Panzera, A.L. Christoforo, F. Scarpa, Thin Wall. Struct. 120, 38-45 (2017)

6. A. Fathi, J-H. Keller, V. Altstaedt, Compos.: Part B 70, 156-166 (2015)

7. G. Rizk, V. Legrand, K. Khalil, P. Casari, F. Jacquemin, Compos. Struct. 186, 233-245 (2018)

8. S.L. Cheng, X.Y. Zhao, Y.J. Xin, S.Y. Du, H.J. Li, Compos. Struct. 129, 157-164 (2015)

9. J. Wang, Ch. Shi, N. Yang, H. Sun, Y. Liu, B. Song, Compos. Struct. 184, 1189-1196 (2018)

10. J. Wals, H-I. Kim, J. Suhr, Compos.: Part A 101, 290-296 (2017)

11. G. Morada, R. Ouadday, A. Vadean, R. Boukhili, Compos.: Part B 114, 418-431 (2017)

12. C. Castellón , M. Medrano, J. Roca, L.F. Cabeza, M.E. Navarro, A.I. Fernández, A. Lázaro, B. Zalba, Renew. Energ. 35, 2370-2374 (2010)

13. A. Carbonari, M. De Grassi, C. Di Perna, P. Principi, Energ. Buildings 38, 472-483 (2006)

14. R. Hamideh Nosrati, U. Berardi, Energ. Buildings 158, 698-711 (2018)

15. K. Chen, A. Neugebauer, T. Goutierre, A. Tang, L. Glicksman, L.J. Gibson, Energ. Buildings 76, 336-346 (2014)

16. P.J. Bjørn, Energ. Buildings 43, 2549-2563 (2011)

17. J. Fricke, T. Tillotson, Thin Solid Films 297, 212-223 (1997)

18. L. Lichołai, J. Szyszka, Lviv Polytechnic National University Institutional Repository 148-152 (2013)

19. J.M. Schultz, K.I. Jensen, F.H. Kristiansen, Sol. Energy Mater. Sol. Cells. 89, 275-285 (2005)

20. L. Lichołai, J. Szyszka, B. Dębska, The manner of production of composite with a sandwich panel structure on the basis of aerogel mat, polyurethane or epoxy resin modified with glycolisate obtained on the basis of waste polyethylene tereph thalate and encapsulated phase change material (PCM), WO 2017043986 A1

21. https://www.dispersionspigments.basf.com/portal/load/fid774774/Catalogue\%20Micronal\%20PCM.pdf (access 2018-01-18)

22. B. Dębska, Poly(ethylene Terephthalate) Based Blends, Composites and Nanocomposites, in: P.M. Visakh, M. Liang (Eds.) Reed Elsevier Inc., 195-212 (2015)

23. B. Dębska, L. Lichołai, Constr. Build. Mater. 65, 604-611 (2014)

24. B. Dębska, L. Lichołai, Constr. Build. Mater. 94, 579-588 (2015)

25. B. Dębska, L. Lichołai, Constr. Build. Mater. 124, 11-19 (2016)

26. B. Dębska, L. Lichołai, Period. Polytech. Civ. Eng. 60, 281-287 (2016)

27. L. Lichołai, B. Dębska, Arch. Civil Mech. Eng. 14, 466-475 (2014)

28. B. Dębska, L. Lichołai, JCEEA 61, 113-120 (2014) 